COSTA, C.A.; RAMOS, J.; ALVES, D.S.; MARTINS, E.R.; FERNANDES, L.A.; LEITE, G.L.D.; NAPOLEÃO, R.L. Produção do maxixe-do-reino em função do sistema de tutoramento e do espaçamento. Horticultura Brasileira, Brasília, v.23, n.1, p.28-31, jan.-mar. 2005.

\title{
Produção do maxixe-do-reino em função do sistema de tutoramento e do espaçamento
}

\author{
Cândido A. da Costa; Sílvio Júnio Ramos; Daniel S. Alves; Ernane Ronie Martins; Luiz Arnaldo \\ Fernandes; Germano L.D. Leite; Reginaldo L. Napoleão \\ UFMG-Núcleo de Ciências Agrárias, C. Postal 135, 39.404-006 Montes Claros-MG; E-mail: candido-costa@nca.ufmg.br.
}

\begin{abstract}
RESUMO
Foram avaliadas as características produtivas do maxixe-do-reino [Cyclanthera pedata L. Schrad.)], em função de sistemas de tutoramento e do espaçamento. O experimento foi conduzido na UFMG em Montes Claros. Empregou-se o delineamento experimental de blocos ao acaso, com quatro repetições e arranjo em faixas $3 \mathrm{x}$ 2 , sendo três sistemas de tutoramento (cerca vertical, cerca cruzada com varas e cerca cruzada com fitilho de polietileno) e dois espaçamentos entre plantas $(1,0 \times 0,5 \mathrm{~m}$ e $1,0 \times 1,0 \mathrm{~m})$, totalizando 24 parcelas. Cada faixa correspondeu a um sistema de condução. As características produtivas dos frutos em número e em peso foram significativamente maiores nas plantas cultivadas no sistema de cerca vertical, onde cada planta produziu, em média, 56 frutos, equivalendo ao peso de $2,68 \mathrm{~kg}$. Nesse sistema houve melhor fixação dos ramos no tutor e menor incidência de frutos danificados por contato com o solo. No espaçamento 1,0 x 1,0 m houve maior rendimento de frutos por planta em número e em peso, resultante do menor efeito competição entre plantas por água, nutrientes e luz. Já, a produtividade por área foi menor devido ao menor número de plantas por ha.
\end{abstract}

Palavras-chave: Cyclanthera pedata, hortaliça não-convencional, sistema de condução.

\begin{abstract}
Yield of achocha as a result of the staking system and spacing

A field experiment was carried out to evaluate the yield of achocha [Cyclanthera pedata L. Schrad.) ] in Montes Claros, Minas Gerais State, Brazil, as a result of the staking system and within-row spacing. The experimental design was of randomized blocks with four replications, arranged in a scheme $3 \times 2$, being three staking systems (vertical fence, pole-trellised fence and polyethylene ribbontrellised fence) and two within-row spacings (1,0 x 1,0 m and 1,0 x $0,5 \mathrm{~m})$, totalizing 24 plots. The fruit number and weight were significantly higher from plants cultivated in the system of vertical fence, where each plant produced 56 fruits on average, corresponding to $2,68 \mathrm{~kg}$. In this system plants presented better fixation to the tutor, besides having minor incidence of damaged fruits caused by the contact with the soil. Highest number, weight of fruits and yield were observed when within-row spacing of 1,0 x 1,0 m was adopted, due to lesser effect of competition between plants for water, nutrients and light. However the yield per area was less due to lower number of plants per ha.
\end{abstract}

Keywords: Cyclanthera pedata, regional vegetable, stakes system.

\section{(Recebido para publicação em 15 de outubro de 2003 e aceito em 16 de novembro de 1004)}

$\mathrm{O}$ maxixe-peruano é uma hortaliçafruto originária da América do Sul. Neste continente, pode ser encontrado, cultivado ou em condição subespontânea, em diversos países, tais como Brasil, Bolívia, Chile, Colômbia, Argentina e Peru. Na forma cultivada destaca-se o Peru, onde é uma espécie de significativo valor econômico. Há registros de seu cultivo ainda na Itália e no México, sendo que, neste último, além dos frutos, os brotos são utilizados como alimento (Klein et al., 1991).

No Brasil, o cultivo dessa hortaliça é realizado por pequenos agricultores, que comercializam seus frutos geralmente em pequena escala. $\mathrm{O}$ fruto apresenta uma diversidade de nomes dependendo da região onde é encontrado, como boga-boga em Tabatinga (AM), cayo em municípios de Rio Branco e Sena Madureira (AC). Na literatura, é denominada às vezes como taiuá-de- comer, chuchu-de-vento, chuchupaulista, chuchu-do-reino, pepino-decomer e pepino-do-ar (Cardoso, 1997).

Segundo Collazos et al. (1975), citados por Klein et al. (1991), o maxixedo-reino é composto por: calorias (15 $\mathrm{g})$, água (95\%), proteínas $(0,5 \mathrm{~g})$, carboidratos $(3,3 \mathrm{~g})$, cálcio (34 mg), fósforo $(43 \mathrm{mg})$, caroteno $(0,06 \mathrm{mg})$, riboflavina $(0,02 \mathrm{mg})$ e niacina $(0,17$ $\mathrm{mg}$ ). A planta também é conhecida por suas propriedades medicinais. É considerado purgativo e seu sabor amargo pode estar relacionado com a presença de compostos fenólicos. A espécie tem ação antiinflamatória, hipoglicemiante e reduz o nível de colesterol (Tommasi et al., 1996).

O maxixe-peruano é tipicamente de clima tropical; não suporta temperaturas muito baixas ou geadas. Mas, há relatos de seu cultivo em condições de clima subtropical, com temperatura média anual de $20^{\circ} \mathrm{C}$ a $25^{\circ} \mathrm{C}$ (Cardoso, 1997; Popenoe et al., 1989).

Embora seja tradicionalmente cultivada no norte de Minas Gerais, poucas informações existem a respeito dessa espécie, principalmente relativas ao manejo e tratos culturais. O sistema de condução e o espaçamento estão entre os fatores que demandam informações técnicas para o cultivo do maxixe-doreino.

Em geral, a cerca cruzada e a cerca vertical são os sistemas de tutoramento mais utilizados no cultivo de hortaliças de hábito trepador, onde são empregados varas de madeira, bambus, arame ou fitilho de polietileno (Sonnenberg, 1985; Cañizares, et al., 1998), dependendo do nível tecnológico do sistema de produção.

Embora represente aumento inicial no custo de produção, o sistema de tutoramento tem sido uma prática van- 
tajosa, pois favorece o controle fitossanitário, facilita alguns tratos culturais, melhora a qualidade do fruto e alonga o período produtivo (Filgueira, 2000).

Cardoso (1997) citou que, pelo fato do maxixe apresentar ramagem vigorosa, é possível esta espécie adequar-se a vários espaçamento e sistema de condução. Normalmente, o espaçamento utilizado no sistema de cerca cruzada é de $1,0 \times 0,5 \mathrm{~m}$.

O presente trabalho teve como objetivo avaliar a produção do maxixe-doreino em função de três sistemas de tutoramento e de dois espaçamentos entre plantas.

\section{MATERIAL E MÉTODOS}

O experimento foi conduzido na UFMGerais em Montes Claros, em altitude de $638 \mathrm{~m}$, de janeiro a junho de 2003, num Argissolo Vermelho Amarelo com as seguintes características: $\mathrm{pH}$ $\left(\mathrm{H}_{2} 0\right)=6,7 ; \mathrm{Ca}^{2+}=4,90 \mathrm{cmol} \cdot \mathrm{dm}^{-3}$; $\mathrm{Mg}^{2+}=1,90 \quad \mathrm{cmol} \cdot \mathrm{dm}^{-3} ; \quad \mathrm{K}^{+}=0,29$ $\mathrm{cmol}_{\mathrm{c}} \cdot \mathrm{dm}^{-3} ; \mathrm{Al}^{3+}=0,00 \mathrm{cmol}_{\mathrm{c}} \cdot \mathrm{dm}^{-3}$ e P/ Mehlich=23,88 mg. $\mathrm{L}^{-1}$.

Empregou-se o delineamento experimental de blocos ao acaso, com quatro repetições, com arranjo em faixas 3 $\mathrm{x} 2$ (três sistemas de tutoramento $\mathrm{x}$ dois espaçamentos), totalizando 24 parcelas. Cada parcela foi constituída por duas linhas de cultivo com três plantas cada, totalizando seis plantas. Os sistemas de tutoramento foram cerca vertical, cerca cruzada com vara e cerca cruzada com fitilho de polietileno e os espaçamentos foram $1,0 \times 1,0 \mathrm{~m} \mathrm{e} 1 \times 0,5 \mathrm{~m}$.

As sementes de acesso local foram semeadas em copinhos de jornal contendo substrato constituído de três partes de terra para uma de húmus de minhoca passados em peneira de malha de $4 \mathrm{~mm}$. As mudas, produzidas em campo aberto, foram transplantadas para o local definitivo quando apresentavam quatro a cinco folhas definitivas, sendo usada uma planta por cova.

Os tutores foram instalados imediatamente antes do transplantio da mudas. No sistema de cerca vertical, foram fincados, a cada seis metros na linha de plantio, moirões de eucalipto tratado, com diâmetro de $15 \mathrm{~cm}$ e $1,80 \mathrm{~m}$ de al-

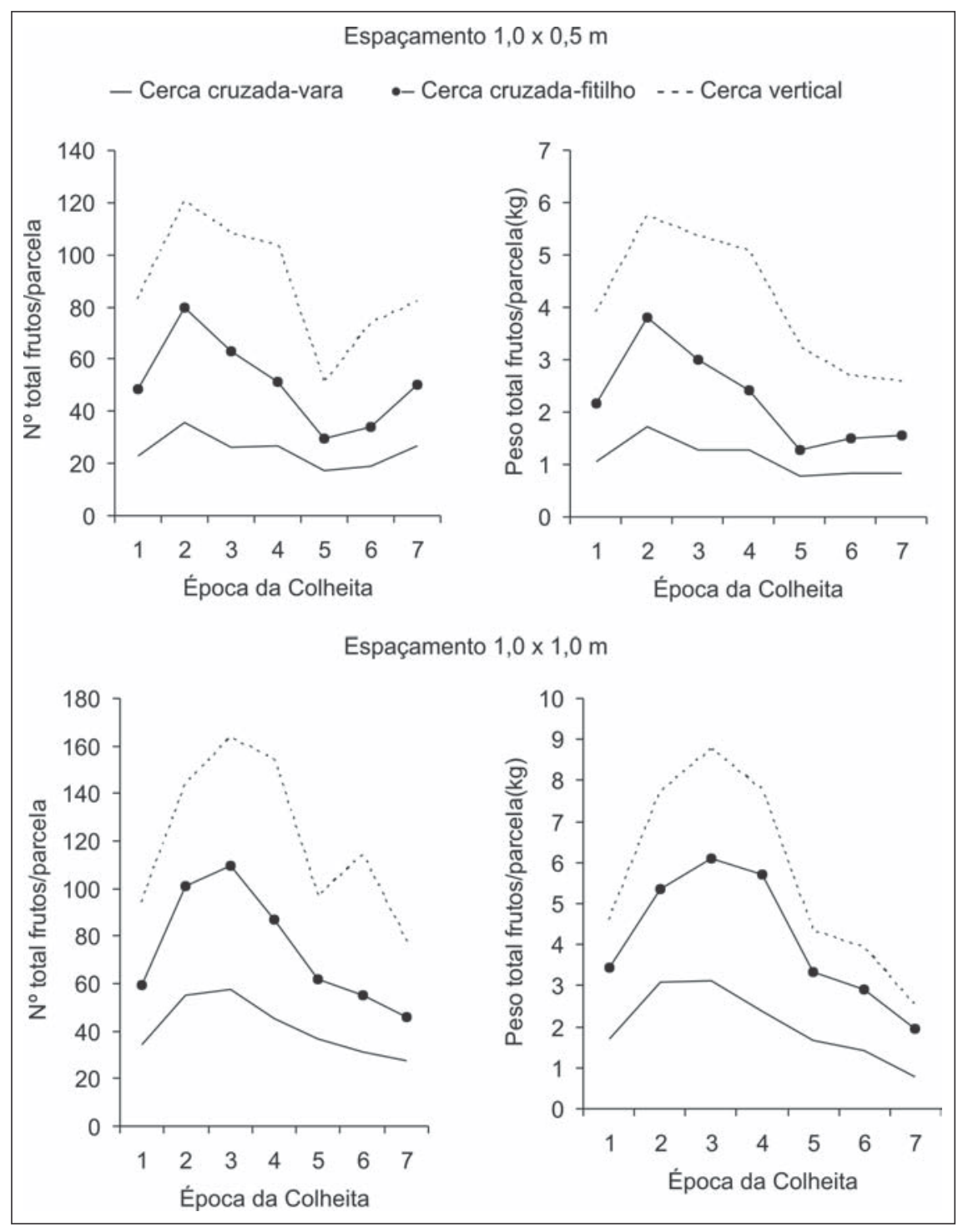

Figura 1. Número e peso totais dos frutos do maxixe-do-reino em cada época de colheita, em função do sistema de tutoramento e do espaçamento. Montes Claros, UFMG-NCA, 2003.

tura. Foram esticados 4 fios de arame $\mathrm{n}^{\mathrm{o}} 16$, igualmente espaçados, a partir de $45 \mathrm{~cm}$ acima da superfície do solo. Ao lado de cada cova foram fincadas varas onde se amarrou a haste principal de cada planta. No sistema de cerca cruza$\mathrm{da}$, foram fincados postes no início e no fim da área experimental, entre duas linhas de plantio. Esticou-se, no topo dos moirões, a uma altura de $1,80 \mathrm{~m}$, um fio de arame $n^{\circ} 16$. Ao lado de cada cova colocou-se uma vara ou um fitilho de polietileno em posição inclinada, ficando sua parte superior apoiada no arame.

A adubação de plantio foi feita nas covas segundo as recomendações para a cultura da abóbora comum (Avelar Filho et al., 1999): $60 \mathrm{~kg} \mathrm{ha}^{-1}$ de $\mathrm{P}_{2} \mathrm{O}_{5}$, de $\mathrm{K}_{2} \mathrm{O}$ e de $\mathrm{N}$, além de $15 \mathrm{tha}^{-1}$ de es- terco de curral. O N e o K foram aplicados $30 \%$ no plantio e o restante aos 40 e aos 80 dias após o transplantio. A irrigação por mini-aspersão foi realizada de acordo com as necessidades da cultura.

Todos os frutos de cada parcela foram colhidos quando ainda imaturos, com comprimento próximo a $12 \mathrm{~cm}$. A colheita iniciou-se aos 100 dias do transplantio em intervalos de sete dias, num total de sete colheitas. Avaliou-se o número de frutos por planta e por área, peso de frutos comerciais por planta e por área, porcentagem de frutos danificados, comprimento e diâmetro médio de frutos. Os resultados foram submetidos à análise de variância e usou-se o teste de Tukey para comparação das médias a $5 \%$ de probabilidade. 
Tabela 1. Produção total em número e peso, comprimento e diâmetro de frutos de maxixe-do-reino em função do sistema de tutoramento. Montes Claros, UFMG-NCA, 2003.

\begin{tabular}{|c|c|c|c|c|c|c|c|c|c|}
\hline \multirow{2}{*}{$\begin{array}{l}\text { Sistema de } \\
\text { tutoramento }\end{array}$} & \multicolumn{3}{|c|}{ Rendimento em número } & \multicolumn{3}{|c|}{ Rendimento em peso (kg) } & \multirow{2}{*}{$\begin{array}{l}\text { Compr. } \\
\text { mm }\end{array}$} & \multirow{2}{*}{$\begin{array}{c}\text { Diâm. } \\
\text { mm }\end{array}$} & \multirow{2}{*}{$\begin{array}{c}\% \text { frutos } \\
\text { danificados }\end{array}$} \\
\hline & $\begin{array}{c}\text { Por } \\
\text { parcela }\end{array}$ & $\begin{array}{c}\text { Por } \\
\text { planta }\end{array}$ & $\begin{array}{l}\text { Por } \\
\text { ha }\end{array}$ & $\begin{array}{c}\text { Por } \\
\text { parcela }\end{array}$ & $\begin{array}{c}\text { Por } \\
\text { planta }\end{array}$ & $\begin{array}{l}\text { Por } \\
\text { ha }\end{array}$ & & & \\
\hline Cerca Vertical & $295 a^{*}$ & $56 a^{*}$ & $713.750 \mathrm{a}^{*}$ & $14,17 a^{*}$ & $2,68 a^{*}$ & $33.857,29 a^{*}$ & $124,38 a^{*}$ & $41,54 a^{*}$ & $8,70 a^{*}$ \\
\hline Cerca Cruzada - Vara & $230 \mathrm{~b}$ & $42 \mathrm{~b}$ & $526.041 \mathrm{~b}$ & $10,91 \mathrm{ab}$ & $2,05 \mathrm{~b}$ & $24.590,63 \mathrm{~b}$ & $120,73 \mathrm{a}$ & 41,47 a & $3,13 a b$ \\
\hline Cerca Cruzada - Fitilho & $207 b$ & $42 \mathrm{~b}$ & $497.083 b$ & $9,38 \mathrm{~b}$ & $1,85 \mathrm{~b}$ & $22.250,00 \mathrm{~b}$ & 117,22 a & 39,93 a & $1,44 \quad b$ \\
\hline C. V (\%) & 28,12 & 21,22 & 29,10 & 28,27 & 22,33 & 27,36 & 3,12 & 3,16 & 38,30 \\
\hline
\end{tabular}

*Médias seguidas da mesma letra na coluna, não diferem entre si, pelo teste de Tukey, a $5 \%$ de probabilidade.

Tabela 2. Produção total em número e peso, comprimento e diâmetro de frutos de maxixe-do-reino em função do espaçamento entre plantas. Montes Claros, UFMG-NCA, 2003.

\begin{tabular}{|c|c|c|c|c|c|c|c|c|c|}
\hline \multirow[b]{2}{*}{ Espaçamento } & \multicolumn{3}{|c|}{ Rendimento em número } & \multicolumn{3}{|c|}{ Rendimento em peso (kg) } & \multirow{2}{*}{$\begin{array}{l}\text { Compr. } \\
\text { mm }\end{array}$} & \multirow{2}{*}{$\begin{array}{c}\text { Diâm. } \\
\text { mm }\end{array}$} & \multirow{2}{*}{$\begin{array}{c}\% \text { frutos } \\
\text { danificados }\end{array}$} \\
\hline & $\begin{array}{c}\text { Por } \\
\text { parcela }\end{array}$ & $\begin{array}{c}\text { Por } \\
\text { planta }\end{array}$ & $\begin{array}{l}\text { Por } \\
\text { ha }\end{array}$ & $\begin{array}{c}\text { Por } \\
\text { parcela }\end{array}$ & $\begin{array}{c}\text { Por } \\
\text { planta }\end{array}$ & $\begin{array}{l}\text { Por } \\
\text { ha }\end{array}$ & & & \\
\hline $1 \times 1,0 \mathrm{~m}$ & $281 a^{*}$ & $53 a^{*}$ & $469.028 b^{*}$ & $13,68 a^{*}$ & $2,56 a^{*}$ & $22.791,67 b^{*}$ & $122,29 a^{*}$ & $41,62 a^{*}$ & $3,93 \mathrm{a}^{*}$ \\
\hline $1 \times 0,5 \mathrm{~m}$ & $207 b$ & $41 \mathrm{~b}$ & 688.889 a & $9,30 \mathrm{~b}$ & $1,83 b$ & $31.006,94 \mathrm{a}$ & 119,25 a & 40,35 a & $4,93 \mathrm{a}$ \\
\hline C. V (\%) & 28,12 & 21,22 & 29,10 & 28,27 & 22,33 & 27,36 & 3,12 & 3,16 & 38,30 \\
\hline
\end{tabular}

*As médias seguidas da mesma letra na coluna, não diferem entre si, pelo teste de Tukey, a 5\% de probabilidade

\section{RESULTADOS E DISCUSSÃO}

O período de colheita dos frutos durou 42 dias, corroborando com os resultados obtidos por Cardoso (1997) no cultivo desta espécie. No maxixe comum (Cucumis anguria L.), também da família cucurbitácea, a colheita prolonga-se por até 60 dias (Filgueira, 2000). $\mathrm{Na}$ última colheita, as plantas apresentavam-se na fase de senescência, tendo como conseqüência reduzido número e peso de frutos em todos os tratamentos (Figura 1).

Não foi observado efeito significativo da interação sistema de tutoramento $\mathrm{x}$ espaçamento em qualquer das características avaliadas.

O sistema de tutoramento influenciou significativamente todas as características avaliadas, exceto o comprimento e o diâmetro médio de frutos (Tabela 1). O rendimento de frutos (número de frutos por parcela, por planta e por ha) foi significativamente maior nas plantas cultivadas no sistema de cerca vertical. Em média, cada planta produziu 56 frutos, equivalendo a 2,68 kg. Cardoso (1997) obteve rendimento de $1,20 \mathrm{~kg}$ de frutos por planta. Os sistemas de cerca cruzada-vara e cerca cruzada-fitilho não promoveram diferenças significativas para número e peso de frutos.
A proporção de frutos danificados devido ao contato com o solo foi significativamente influenciada pelo sistema de tutoramento. No sistema de cerca cruzada com fitilho os danos foram bem maiores do que na cerca vertical (Tabela 1).

As maiores produções obtidas nas plantas cultivadas no sistema de cerca vertical foram provavelmente devido à melhor fixação das plantas nesse sistema e, conseqüentemente, à melhor distribuição dos ramos no tutor, o que facilitaria a polinização das flores pelos insetos. A família Cucurbitaceae compreende espécies que têm alta dependência de insetos para a polinização (Wien, 1997).

Nos outros sistemas, principalmente a cerca cruzada com fitilho, as plantas ficaram mais concentradas na base do tutor e com alta incidência de ramos no chão. Essa má distribuição dos ramos resultou em maior perda de frutos devido ao contato direto com o solo, além de dificultar a visita de insetos nas flores.

Cabe ressaltar que todos os tratamentos tiveram o amarrio inicial para fixar a planta jovem ao tutor. À medida que a planta crescia, a fixação se dava primordialmente pelas gavinhas dos ramos. Na cerca cruzada com fitilho haveria a necessidade de constante orientação dos ramos no tutor para melhor fixação, o que resultaria em maior demanda de mão-de-obra. Já na cerca ver- tical, apenas o amarrio inicial foi suficiente para que os ramos se fixassem nos arames. Além da economia de mão-deobra, a cerca vertical apresenta a vantagem da durabilidade do material empregado. Coutinho et al. (2003), utilizando dois sistemas de tutoramento na cultura do inhame, concluíram que a cerca vertical de arame proporcionou ganho no custo de implantação, comparativamente à cerca com varas, por permitir a reutilização deste material por até seis anos.

Quanto ao espaçamento, as produções de frutos totais e por planta foram significativamente maiores nas plantas provenientes do espaçamento de $1,0 \mathrm{x}$ 1,0 m (Tabela 2). Tais resultados podem ser atribuídos à menor competição entre as plantas de maxixe-do-reino por água, nutrientes e luz. Isso justifica o menor rendimento em número de frutos por parcela e por planta obtidos no menor espaçamento $(1,0 \times 0,5 \mathrm{~m})$ (Tabela 2). O decréscimo da produtividade por planta em função do aumento da densidade de semeio foi constatado por Pereira et al. (2003) na cultura do meloeiro. Tais autores atribuíram esses resultados às pressões de competição inter e intraplantas.

O tamanho do fruto, representado pelo comprimento e diâmetro, bem como o peso médio do fruto, não apre- 
sentaram qualquer influência significativa do espaçamento entre plantas. Leal e Rego (2001), avaliando o efeito de espaçamentos entre plantas nas características produtivas do maxixe comum, não observaram efeito significativo no peso médio dos frutos. Extrapolando os resultados para rendimento por hectare, ficou bastante evidente o efeito da maior densidade de plantas, quando a diminuição do espaçamento de 1,0 para $0,5 \mathrm{~m}$ entre plantas resultou em aumento de 220 frutos e peso de $8.215 \mathrm{~kg}$ a mais (Tabela 2).

Uma vez que o maior adensamento não interferiu nas características individuais do fruto, como comprimento e diâmetro, pode-se adotar tal espaçamento visando maior produção de frutos por área.

\section{LITERATURA CITADA}

AVELAR FILHO, J.A.; MELO, A.M.T. FILGUEIRA, F.A.R. Sugestões de adubação para hortaliças - Abóbora menina. In: RIBEIRO, A.C.; GUIMARÃES, P.T.G.; ALVAREZ, V.H. (Ed.) Recomendações para o uso de corretivos e fertilizantes em Minas Gerais - $5^{a}$ aproximação (Comissão de Fertilidade do solo do estado de Minas Gerais): Viçosa, 1999. 359 p.
CAÑIZARES, K.A.L. A cultura do pepino. In: GOTO, R.; TIVELLI, S.W.. (Ord.). Produção de hortaliças em ambiente protegido: condições subtropicais. São Paulo: Fundação Editora da UNESP, 1998. p.195-1224.

CARDOSO, M.O. Maxixe-peruano (Cyclanthera pedata (L.) Schrad.). In: CARDOSO, M.O. (Coord.) Hortaliças não convencionais da Amazônia. Brasília: EMBRAPA - CPAA, 1997. p.105-111.

COUTINHO, G.V.; MELHO, G.S.; TABOSA, J.N.; MENEZES, D.; SIMPLÍCIO, J.B.; REIS, O.V.; ANUNCIAĈ̃̃O FILHO, C.J.; GOMES, R.V.; OLIVEIRA, J.P. Uso do arame no espaldeiramento do inhame (Dioscorea spp.) em Pernambuco - comparativo com o sistema tradicional de cultivo. In: CONGRESSO BRASILEIRO DE OLERICULTURA, 43, 2003, Recife. Anais eletrônicos... Recife: SOB, 2003. Disponível em: <http://www.horticiencia.com.br/anais/arquivos/olfg4006c.pdf $>$. Acesso em 20 mar. 2004 FILGUEIRA, F.A.R. Novo manual de olericultura: agrotecnologia moderna na produção e comercialização de hortaliças. Viçosa: UFV, 2000. 402 p.

KLEIN, V.L. GOMES; BRANDÃO M; LACABUENDIA, J.P. Cyclanthera pedata var. edulis (Naud.) Cogn. Uma curcubitaceae pouco conhecida na alimentação humana. Daphne, Belo Horizonte, v.1, n.2, p.8-13, 1991.

LEAL, F.R.; RÊGO, M.C.A. Influência de diferentes espaçamentos no comportamento do maxixe conduzido em ambiente com meia sobra Horticultura Brasileira, Brasília, v.19, suplemento CD-ROM, julho, 2001.
PEREIRA, F.H.F.; NOGUEIRA, I.C.C.; PEDROSA, J.F.; NEGREIROS, M.Z.; BEZERRA NETO, F. Poda da haste principal e densidade de cultivo sobre a produção e qualidade de frutos em híbridos de melão. Horticultura Brasileira, Brasília, v.21, n.2, p.191-196, 2003.

POPENOE, H.; KING, S.R.; LEÓN, J.; KALINOWSKI, L.S. Lost crops of the Incas littleknown plants of the Andes with promise for worldwide cultivation. National Academy Press: Washington D.C., 1989. 409 p.

SONNENBERG, P. Olericultura especial. $2^{\mathrm{a}}$ parte. $3^{\text {a }}$ Ed., Goiânia: UFG, 1985. 149 p. (Informações Técnicas)

TOMMASI, N.; SIMONE, F.; SPERANZA, G.; PIZZA, C. Studies on the constituents of Cyclanthera pedata (Caigua) seeds: isolation and characterization of six new cucurbitacin glycosides. Journal of Agricultural and Food Chemistry. v.44, n.8, p.2020-2025. 1996.

WIEN, H.C. The cucurbits: Cucumber, melon, squash and pumpkin. In: Wien, H.C. (Ed.) The physiology of vegetables crops. Cab International: Cambridge, 1997. p.345-386. 